\title{
Image guided robotic surgery: Current evidence for effectiveness in urology
}

\author{
Anum Pervez, Kamran Ahmed, Stephen Thompson, Oussama Elhage, \\ M. Shamim Khan, Prokar Dasgupta \\ MRC Centre for Transplantation, NIHR Biomedical Research Centre, King's Health Partners, King's College London \\ and Department of Urology, Guy's Hospital, St Thomas Street, London SE1 9RT
}

\begin{abstract}
Summary Objectives: Discussion of the evolution of image guided surgery (IGS) and its fundamental components and current evidence for effectiveness of IGS in clinical urology.

Methods: Literature search for image-guided robotic urology. Results: Current literature in image-guided robotic urology with its use in robot assisted radical prostatectomy and robot assisted partial nephrectomy are shown.

Conclusions: Image guided surgery can be a useful aid to improve visualisation of anatomy and subsurface structures during minimally invasive surgery. Soft-tissue deformation makes it difficult to implement IGS in urology but current studies have shown an attempt to address this issue. The feasibility of IGS requires randomised control trials assessing in particular its accuracy and affect on clinical outcome.
\end{abstract}

KEY WORDS: Robotic; Iimage-guided surgery, Registration; Tracking; Llocalisation error; Augmented reality.

Submitted 6 April 2014; Accepted 30 September 2014

\section{INTRODUCTION}

The benefits of minimally invasive surgery include shorter hospital stay, decreased intra-operative blood loss and less post-operative pain when compared to conventional open surgery. However, an advantage afforded to the open surgical technique is the ability to directly visualise structures. In minimally invasive surgery, the surgeon's field of view becomes compromised as it is relies on scoped cameras to produce an display (1).

Recent advances in image-guided surgery (IGS) may offer a solution to improve visualisation. IGS technology merges pre-operative and/or intra-operative images in order to create a 3D reconstruction of the patient's internal structures and subsurface anatomy. These images can be used alone with tracked surgical instruments or superimposed over a laparoscopic video feed to create a display referred to as augmented reality (AR). The principle benefit of such a system is the ability to see beyond the surgical plane and visualise internal structures such as organs, tissues, nerves and muscle (2). The use of IGS is currently being explored in a number of surgical specialities and aims to improve surgical accuracy as well as guide procedures intra-operatively. This article discusses the concept of IGS and its effectiveness in the clinical urology.

\section{THE EVOLUTION OF IGS}

The advent of IGS began in the neurosurgical field. Minimally invasive techniques were developed to overcome the high-risk of brain injury sustained during open neurosurgical procedures. By adapting various imaging modalities, it became possible to guide the surgery intraoperatively and hence improve the system accuracy (3). Image-guided neurosurgery uses pre-operative MRI or CT images of the patient's brain, which show localisation of the tumour lesion to reconstruct a 3D model of the patient's anatomy. The surgeon can then plan the procedure, viewing it from different angles and deciding on the exact point of entry, relative to other important structures, such as the brainstem. Also, instruments used during the procedure can be tracked in real time to avoid damage to other tissue (3). Neurosurgical procedures, which have shown success using this technique include, stereotactic biopsy, shunt placement and craniotomy. Adapting IGS for specialities other than neurosurgery has been challenging. However, early studies of IGS in fields such as cardiac surgery and liver surgery have shown promise. In particular with the rapid development of robotic urology, there has been a need for better visualisation. Hence the ability to combine IGS and robotics could provide an essential technique for the future direction of urology (4).

\section{FUNDAMENTAL COMPONENTS OF IGS}

IGS relies on several key engineering concepts, which must all be synchronized for the system to work.

These are:

1) Imaging

2) Image processing (segmentation)

3) Registration and tracking

4) User interface and display

\section{1) Imaging}

There are several different imaging modalities. Tissue penetration, spatial resolution (ability to distinguish two 
points) and tissue boundaries (contrast) are key features when choosing which approach to use. Optical imaging has low tissue penetration and therefore would not be suitable for IGS. CT, MRI, X-ray and US on the other hand, have much better penetration of tissue structures and are therefore more suitable for IGS. The most commonly used techniques in IGS and their attributes are shown in Table 1. Along with the quality of the image produced, factors such as cost, radiation exposure and feasibility of use within the operating theatre will all come into play when creating an IGS system $(1,5,6)$.

\section{2) Image processing}

Once the pre-operative images are acquired, a 3D model of the patient's anatomy can be reconstructed using segments of the data. At present, the majority of cases require manual segmentation by radiologists. However, the need for faster automated segmentation is becoming more evident and in particular as a means to overcome the potential for human error (7).

\section{3) Registration and tracking}

Registration aligns pre-operative images with the patients anatomy to create a $3 \mathrm{D}$ coordinated space (8). It is achieved by matching specific anatomical or fiduciary landmarks on the imaging with the corresponding points on the patient. For example, the tragus of the ear or the outer canthi of the eye are commonly used (9). These images can also be registered with intra-operative images or in the case of a laparoscopic procedure, superimposed over a video feed. Image registration is classified into rigid and non-rigid categories. A rigid system assumes the position/shape of the subject remains unchanged and as such registration is relatively simple. For example in neurosurgery, the brain stays mostly unchanged between scans and when a stereotactic frame is attached to the patient's skull, fiduciary markers can easily be aligned with CT/MRI pre-operative images. Another field, which has also been able to exploit IGS, is orthopaedics because again the anatomy remains fixed (17). The need for non-rigid registration has developed because most structures in the body are in fact dynamic and susceptible to soft tissue deformation during surgery. Non-rigid registration is much more complex and time-consuming (10). This has been the main challenge of using IGS in surgical fields such urology, cardiac and general surgery. Furthermore, many of the current registration models require manual overlay and hence the potential for human error can affect the accuracy of the system. In cases where there are no intraoperative images available, the pre-operative images are registered just to an instrument tracking system. Tracking allows for the exact location of surgical instruments to be determined. The surgeon can therefore be guided in real-time during the procedure. The commonest tracking materials are optical and magnetic. The optical system uses a specialised tool with a camera and a tracker. The surgeon holds the proximal end of the tool with the camera and the distal tracker is placed inside the patient. However, direct line of sight is necessary between the camera and the tracker, which can be difficult in the operating theatre. The newer method of magnetic tracking does not require direct of line of sight but electromagnetic forces can vary with the presence of metallic objects in the operating room (8). The surgical accuracy of optical and magnetic tracking systems $(<3 \mathrm{~mm}$ considered good) was compared by Mascott in 2005. The results of this study show the optical tracking system had an accuracy of $1.4 \pm 0.8 \mathrm{~mm}$ and the magnetic system had $1.4 \pm 0.6$ $\mathrm{mm}$ (root mean square), and hence both systems are consider highly accurate (11). However accuracy of the tracking devices is application specific and can vary.

\section{4) User interface and display}

The previous 3 steps must all be coordinated onto a user interface. It is important the user interface is designed for ease of control, rather than creating a distraction for the surgeon. The data is then available to view on a display console as an AR. This includes the imaging material, a view of the tracked surgical instruments and in the case of laparoscopic surgery it is superimposed over the video feed. The AR must also be able to provide real-time updates during the procedure. An example of a display screen is illustrated in Figure 1 showing a robotic radical

Table 1. Imaging modalities $(1,5,6)$.

\begin{tabular}{|c|c|c|c|c|c|}
\hline Imaging technique & Tissue penetration & Spatial resolution & Tissue boundary differentiation & Advantages & Disadvantages \\
\hline CT & $\begin{array}{c}\text { Complete } \\
++++\end{array}$ & $0.25 \mathrm{~mm}$ & +++ & $\begin{array}{l}\text { 3-dimensional } \\
\text { Can use contrast agent } \\
\text { Cheaper than MRI }\end{array}$ & lonizing radiation \\
\hline MRI & $\begin{array}{c}\text { Complete } \\
++++\end{array}$ & $0.5 \mathrm{~mm}$ & ++++ & 3-dimensional & $\begin{array}{c}\text { Expensive } \\
\text { Intrusive in operating room }\end{array}$ \\
\hline X-ray fluoroscopy & $\begin{array}{c}\text { Complete } \\
++++\end{array}$ & $0.1 \mathrm{~mm}$ & ++ & $\begin{array}{c}\text { Low cost } \\
\text { Can use contrast agent }\end{array}$ & $\begin{array}{l}\text { Ionizing radiation } \\
\text { 2-dimensional }\end{array}$ \\
\hline US & $\begin{array}{c}2-20 \mathrm{~cm} \text {, No bone } \\
+++\end{array}$ & $20 \mu \mathrm{m}-0.5 \mathrm{~mm}$ & +++ & $\begin{array}{c}\text { Non-ionising } \\
\text { 3-dimensional } \\
\text { Dynamic imaging } \\
\text { Small portable device }\end{array}$ & $\begin{array}{l}\text { Poor bone penetration } \\
\text { User dependant }\end{array}$ \\
\hline PET & $\begin{array}{c}\text { Complete } \\
++++\end{array}$ & $5-10 \mathrm{~mm}$ & & $\begin{array}{l}\text { Can accurately define lesions } \\
\text { when combined with CT/MRI }\end{array}$ & Ionising radiation \\
\hline Optical & $\begin{array}{c}\leq 5 \mathrm{~mm} \\
++\end{array}$ & $10 \mu \mathrm{m}$ & ++++ & $\begin{array}{l}\text { High quality images } \\
\text { of direct vision }\end{array}$ & Lack of penetration \\
\hline
\end{tabular}




\section{Figure 1.}

Display screen for laproscopic radical prostatectomy with pre-operative MRI image overlay and surgical tool tracking (12).

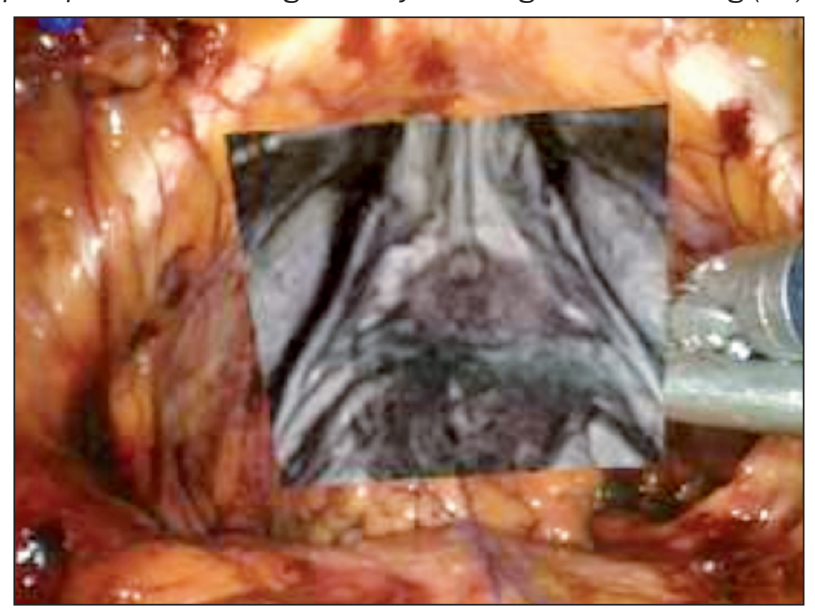

Figure 2.

Concept of the image guided surgery system.

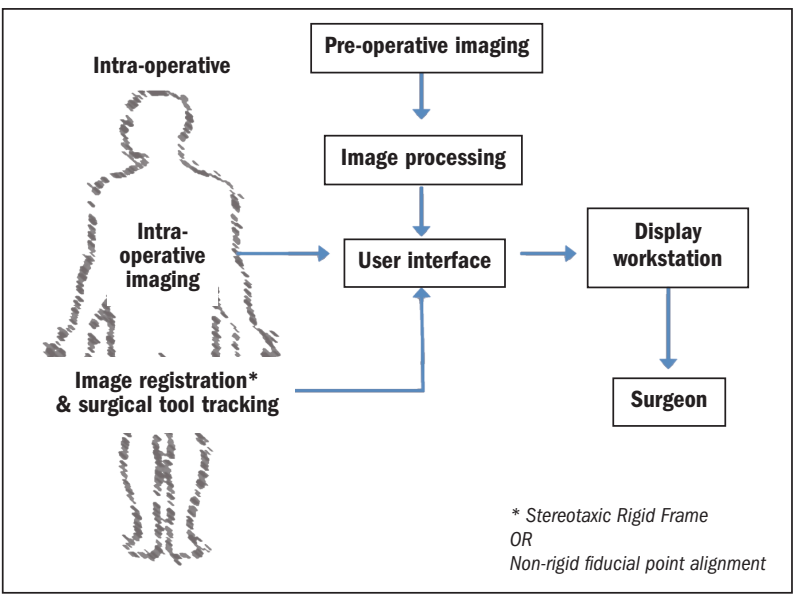

prostatectomy. The pre-operative MRI scan is superimposed over the laparoscopic video screen (12).

Once all the components of IGS are merged (shown in Figure 2), the surgeon can then use the system to plan, guide and perform surgery.

\section{Clinical effectiveness}

\section{OF IMAGE GUIDED ROBOTIC UROLOGY}

The current application of IGS in robotic urology has been analysed in table 2, with its consideration in robot assisted prostatectomy and robot assisted partial nephrectomy. A variety of imaging modalities have been considered, ranging from CT to ultrasound but development is in the early stages with relatively small studies, aimed mainly to assess the feasibility of IGS in urology. A necessary attribute for the validity of the IGS system is accuracy. Accuracy becomes more difficult with non-rigid registration with dynamic and soft tissue deformation. This is a particular issue in urology because the soft tissue is in constant flux. Teber et al. (13) proposed a technique to overcome the issue of tissue deformation by using navigation aids. Needle-like markers were inserted directly into the target organ, in this case the kidney and could be tracked intra-operatively using a mobile C-arm with cone beam imaging. Along with pre-operative CT images, all the information was integrated in real time as an image overlay over the endoscopic view. Although this method is good at addressing the issue of tissue deformation, its downside is that 3D AR is superimposed over a 2D endoscopic view. Another technology that has shown a great deal of promise is the Firefly imaging system. Patients are injected with intravenous indocyanine green (ICG) dye, which binds to plasma proteins in the blood. A nearinfrared fluorescent (NIRF) camera is integrated with the da Vinci ${ }^{\circledR}$ surgical system and blood vessels are illuminated intra-operatively. Not only does this improve tumour margins, but also allows for selective clamping of vessels to confine the area of ischemia. It is important to note fluorescent imaging is inadequate as a sole replacement for white light, rather it offers be to be a great adjunct that can be turned on/off as needed during the procedure (14). Current research into IGS explores the compatibility of various systems and their accuracy. However, the true effectiveness of IGS will be based upon improvements to clinical outcome. Evidence from Table 2 show two studies, Teber et al. (15) and Hung et al. (16), in which the majority, if not all the patients had tumour-free margins. The ability to assess clinical outcome is limited in these cases because of the small sample size and the lack of

Table 2. Current literature in image-guided robotic urology.

\begin{tabular}{|c|c|c|c|c|c|c|}
\hline Author & Speciality & Procedure & Sample size & Imaging modality & Accuracy & Clinical outcome \\
\hline Thompson et al. (12) & Urology & $\begin{array}{l}\text { Robot assisted } \\
\text { prostatectomy }\end{array}$ & 13 human patients & Pre-op MRI & RMS error 5 mm & $\begin{array}{l}\text { No measureable change } \\
\text { in clinical outcome but } \\
\text { helpful to the surgeon }\end{array}$ \\
\hline Teber et al. (13) & Urology & $\begin{array}{l}\text { Robot assisted laparoscopic } \\
\text { partial nephrectomy }\end{array}$ & $\begin{array}{l}10 \text { porcine models and } \\
10 \text { human patients }\end{array}$ & Pre-op CT & Error margin $0.5 \mathrm{~mm}$ & $\begin{array}{l}\text { Tumour-free margins } \\
\text { in all } 10 \text { cases }\end{array}$ \\
\hline Tobis et al. (14) & Urology & $\begin{array}{l}\text { Robot assisted laparoscopic } \\
\text { partial nephrectomy }\end{array}$ & 11 human patients & $\begin{array}{l}\text { Intra-op near infrared } \\
\text { fluorescence imaging }\end{array}$ & - & $\begin{array}{l}\text { Improved visualisation } \\
\text { of renal vasculature \& } \\
\text { ability to differentiate } \\
\text { renal tumours from } \\
\text { normal parenchyma }\end{array}$ \\
\hline Su et al. (15) & Urology & $\begin{array}{l}\text { Robot assisted laparoscopic } \\
\text { partial nephrectomy }\end{array}$ & 2 human patients & Pre-op CT & $1 \mathrm{~mm}$ & - \\
\hline Hung et al. (22) & Urology & Robot assisted prostatectomy & 10 human patients & Intra-op TRUS & - & $\begin{array}{l}\text { Negative margins } \\
\text { in } 9 / 10\end{array}$ \\
\hline
\end{tabular}


control groups. A study by Thompson et al. (12) on the other hand reported no changes to clinical outcome. They did highlight however, that the IGS system was found to be very helpful by the operating surgeon.

\section{Challenges in image-guided robotic urology}

The IGS system does have some challenges, which need to be addressed. One of the main considerations is creating a highly accurate system for image registration, which accounts for soft tissue deformation. As the majority of current IGS requires manual processing and registration, it can be susceptible to human error. For example, if the image is aligned in the wrong location or the wrong blood vessels displayed, it can have devastating affects on the surgical outcome. Furthermore, the computer interface must be relatively easy to operate by the surgeon. If the system is complex it may act as a rather dangerous distraction. Therefore a simple but yet accurate system is As previously discussed, the current trials using IGS have small sample sizes. This makes studying the efficacy of the system difficult. Therefore randomised clinical trials comparing IGS to non-IGS are required to assess there is an improvement to clinical outcome. Table 1 has also highlighted some issues with the imaging modalities that are currently being used for IGS. For example radiation risk of intra-operative CT scans and the size of MRI machines in the operating theatre. These issues create difficulty for IGS to be adopted widely. A question yet to be considered, is the cost of these systems. The cost of implementing IGS in most cases is negligible as the imaging modalities and surgical tools are already in common practise. However, the purpose of IGS is to offer minimally invasive surgery to a patient who would have otherwise required open surgery. Therefore analysing the improvement to clinical outcome will be difficult to perform. For example, if IGS is successful in improving tumour resection margin, it could potentially improve cancer outcomes but this will require a long-term study design for conclusive evidence.

\section{FUTURE OF IGS}

IGS has the potential to resolve the visibility issues encountered in robotic urology. However for the IGS system to be adopted, further research must be performed on creating a successful automated system that can integrate with the intra-operative interface and account for soft tissue deformation. Simulations and training may also be a future use of IGS. The creation of an augmented virtual reality model could offer an excellent teaching tool. Therefore procedures and therapies could be trialled on virtual reality simulators before being transferred to patients (9).

\section{ACKNOWLEDGEMENTS}

Nicholas Chang, Medical student, Kings College London. This research was supported by the National Institute for Health Research (NIHR) Biomedical Research Centre based at Guy's and St Thomas' NHS Foundation Trust and King's College London. The project is also supported by the SIMULATE (National initiative for simulation training in urology), The Urology Foundation (TUF) and the Royal College of Surgeons of England. The views expressed are those of the author(s), based on the research outcomes.

\section{References}

1. Perrin DP1, Vasilyev NV, Novotny P, et al. Image guided surgical interventions: Curr Probl Surg. 2009; 46:730-66.

2. Medtronic. Image-Guided Surgery Overview [cited 201224 November]. Available from: http://wwwp.medtronic.com/Newsroom/ LinkedItemDetails. do?itemId=1101831118967 Eitem Type $=$ backgrounderElang=en_US.

3. De Nigris D, Collins D, Arbel T. Multi-modal image registration based on gradient orientations of minimal uncertainty. IEEE Trans Med Imaging. 2012; 31:2343-54.

4. Ukimura O. Image-guided surgery in minimally invasive urology. Curr Opin Urol. 2010; 20:136-140.

5. Voxelera. Part I: Commonly used radiological imaging modalities Jan 2006 [cited 2012 Dec 5th]. Available from: http://www.voxelera.co.uk/downloads/tablepart1_jan2006.pdf.

6. Voxelera. Part II: Less commonly used in vivo imaging modalities May 2006 [cited 2012 Dec 5th]. Available from: http://www.voxelera.co.uk/downloads/tablepart2_may2006.pdf.

7. Thompson S, Penney G, Buie D, et al. Use of a CT statistical deformation model for multi-modal pelvic bone segmentation. In: Medical Imaging 2008: Image Processing.; vol. 6914 of Proceed-ings of the SPIE. 2008

8. Herrell SD, Galloway RL, Su LM. Image-guided robotic surgery: update on research and potential applications in urologic surgery. Curr Opin Urol. 2012; 22:47-54.

9. Peters TM. Image-guided Surgery and Therapy: Current Status and Future Directions. In: Mun SK, editor. Medical Imaging 2001: Visualization, Display, and Image-Guided Procedures; San Diego, CAFebruary 17, 2001.

10. Crum WR, Hartkens T, Hill DL. Non-rigid image registration: theory and practice. Br J Radiol. 2004; 77 Spec No 2:S140-53.

11. Mascott CR. Comparison of magnetic tracking and optical tracking by simultaneous use of two independent frameless stereotactic systems. Neurosurgery. 2005; 57:295-301; discussion 295-301.

12. Thompson S1, Penney G, Billia M, et al. Design and evaluation of an image guidance system for robot assisted radical prostatectomy. BJU Int. 2013; 111:1081-90.

13. Teber D, Guven S, Simpfendörfer T, et al. Augmented Reality: A New Tool To Improve Surgical Accuracy during Laparoscopic Partial Nephrectomy? Preliminary In Vitro and In Vivo Results. Eur Urol. 2009; 56:332-338.

14. Tobis S, Knopf J, Silvers C, et al. Near infrared fluorescence imaging with robotic assisted laparoscopic partial nephrectomy: initial clinical experience for renal cortical tumors. J Urol. 2011; 186:27-52.

15. Su LM, Vagvolgyi BP, Agarwal R, et al. Augmented reality during robot-assisted laparoscopic partial nephrectomy: toward real-time 3DCT to stereoscopic video registration. Urology. 2009; 73:896-900.

16. Hung AJ, Abreu AL, Shoji S, et al. Robotic transrectal ultrasonography during robot-assisted radical prostatectomy. Eur Urol. 2012; 62:341-8.

17. Villavicencio AT, Burneikiene S, Bulsara KR, Thramann JJ. Utility of computerized isocentric floroscopy for minimally invasive spinal surgical techniques. J Spinal Disord Tech. 2005; 18:369-75.

\section{Correspondence}

Kamran Ahmed, MRCS, PhD (Corresponding Author) - kamran.ahmed@kcl.ac.uk Anum Pervez, BSc - Stephen Thompson, PhD - Oussama Elhage, MRCS M Shamim Khan, OBE, FRCS (Urol), FEBU - Prokar Dasgupta. MD, FRCS (Urol), FEBU

MRC Centre for Transplantation, NIHR Biomedical Research Centre, King's Health Partners, King's College London and Department of Urology, Guy's Hospital, St Thomas Street, London SEl 9RT 